\title{
Gömülü Meziodensler Tarafından Kompleksleştirilmiş Bir Kron Kırı̆ğ Olgusunun Tedavisi
}

\section{Treatment of a Tooth With Crown Fracture Complicated By the Presence of the Impacted Mesiodens}

\section{ÖZ}

Çocuklar sıklıkla dental travmaya maruz kalmaktadır ve travmaya maruz kalan diş zamanında tedavi edilmediğinde ciddi komplikasyonlar oluşabilmektedir. Açık kapanış, üst kesici dişlerin protrüzyonu ile artmış over jet, yetersiz dudak kapanışı gibi faktörler travma olguları ile ilişkili predispozan faktörler olarak tanımlanmaktadır. Son yıllarda mesiodens vakalarının dental travma konusunda hem oluşum hem de tedavi sürecinde risk oluşturabileceği yönündeki yayınlar literatürde yer almakla birlikte sınırlı sayıdadır. Bu olgu raporunda, komplike olmayan kron kırığg bulunan, apeksifikasyonu tamamlanmamış santral dişin geç tedavisi sebebiyle meydana gelmiş olan kistik oluşum ve bununla ilişkilenmiş gömülü mesiodens dişlerin multidisipliner tedavisi sunulmuştur. On bir yaşındaki çocuk hastanın tedaviden sonraki bir yıllık takibi sonucunda klinik ve radyografik bulgular tedavi protokolünün uygunluğunu işaret etmektedir.

Anahtar sözcükler: Meziodens, Travma, Komplike olmayan kron kırığı, Çocuk.

\begin{abstract}
Children often have traumatic dental injuiries and if teeth, which exposed to trauma leaved untreated; serious complications can occur. Factors such as open bite, increasing overjet with protrusion of upper incisors, and insufficient lip closure are identified as predisposing factors associated with trauma cases. In recent years, there is evidence indicating mesiodens as a risk factor in both the treatment and occurence of trauma but it is limited. The purpose of this article was to present the multidisciplinary management of a cyst which has occurred due to late treatment of central tooth with uncomplicated crown fracture and associated with impacted mesiodenses. As a consequence of trauma, the central incisor's root development was prematurely arrested and had open apex. The case was followed up to 1 year after treatment which showed a good clinical and radiographic examination and that indicates the suitability of the treatment protocol.
\end{abstract}

Key words: Mesiodens, Trauma, Uncomplicated crown fracture, Child.

\section{GíRiş}

Travmatik dental yaralanmalar arasında kron kırıkları en sık görülen yaralanma tipidir ve literatürde görülme sıklığı \%26-76 oranında bildirilmektedir (1,2). Özellikle 7-10 yaş arası çocuklarda henüz daimi keser dişlerin kök gelişiminin tamamlanmadığı dönemde görülmektedir (3). Komplike olmayan kron kırıkları pulpa ekspozu içermese de tedavi
Mesut ELBAY ${ }^{1}$

Ülkü ŞERMET ELBAY ${ }^{1}$

Ceren UĞURLUEL ${ }^{1}$

Bahadir KAN ${ }^{2}$

Eser TUTUŞ²

1 Kocaeli Üniversitesi Tip Fakültesi, Çocuk Diş Hekimliği Anabilim Dalı, Kocaeli, Türkiye

2 Kocaeli Üniversitesi Tip Fakültesi, Ağız Diş ve Çene Cerrahisi Anabilim Dalı, Kocaeli, Türkiye

Geliş tarihi / Received: 26.02.2018 Kabul tarihi / Accepted: 30.03.2018 DOI: $\operatorname{xxxxxxxxxxx}$

İletişim Adresi/Corresponding Adress:

Ülkü Şermet Elbay

Kocaeli Üniversitesi Tip Fakültesi, Çocuk Diş Hekimliği Anabilim Dalı, Kocaeli, Türkiye

Tel/Phone: 026234422 22/ 5162-3

E-posta/e-mail: ulkusermet_3@msn.com 
edilmediğinde açık olan dentin tübülleri aracılığıyla pulpa dokusuna bakteri ve toksin geçişi olabilmekte ve buna bağlı uzun dönemde pulpa nekrozu ve periapikal lezyon meydana gelebilmektedir (4). Bu durum kök maturasyonu tamamlanmamış bir dişte hem endodontik tedavi açısından zorluklar oluşturmakta hem de gelecekte ince kalmış kök kanal duvarları nedeniyle kırığa yatkınlık oluşturmaktadır (5).

Travmatik dental yaralanmalar çocuk hastalarda yaygın görülmekle birlikte özellikle açık kapanış, üst kesici dişlerin protrüzyonu ile artmış over jet, yetersiz dudak kapanışı gibi faktörler travma olguları ile ilişkili predispozan faktörler olarak tanımlanmaktadır (1). Son yıllarda mesiodens vakalarının dental travma konusunda hem oluşum hem de tedavi sürecinde risk oluşturabileceği yönündeki yayınlar literatürde yer almaktadır $(6,7)$. Mesiodens maksiller anterior bölgede çoğunlukla santraller dişler arasında bulunan sürnümerer dişler olarak tanımlanmaktadır ve literatürde görülme sıklığ $1 \% 0,1$ 3,8 arası rapor edilmektedir $(8,9)$. Çoğu zaman gömük olarak kalabilmekte, birden fazla meydana gelebilmekte ve genellikle asemptomatik olduğu için dental muayene sırasında teşhis edilebilmektedir (10). Sürmemiş meziodenslere komşu olan dişlerde kök rezorpsiyonu, ektopik sürme, diastema, gömülü kalma, bunlara bağlı olarak estetik problemler ve kistik oluşumlar gibi komplikasyonlara sebebiyet verebilmektedir (11). Gömülü mesiodenslerin tedavisinde komşu dişlerin apeksfikasyonunun tamamlanması ve ardından cerrahi müdahale ile gömülü mesiodenslerin eksize edilmesi tavsiye edilmektedir (12). Küçük çocuklarda cerrahi müdahalelerin psikolojik açıdan tolerasyonunun zor olduğu da göz önünde bulundurulursa gömülü mesiodensler pedodontistler açısından tedavi protokolü açısından kompleks bir hale gelebilmektedir (7). Tek başına travma ya da mesiodens varlığı bile çocuk hastada tedavi açısından sıkıntılar barındırırken, her iki durumun bir arada olduğu durumlarda tedaviler daha komplikeleşmekte ve multidisipliner yaklaşım gerektirmektedir.
$\mathrm{Bu}$ olgu raporunda, komplike olmayan kron kırı̆̆ 1 bulunan, apeksifikasyonu tamamlanmamış santral dişin tedavi için gecikmesi nedeniyle meydana gelmiş olan kistik oluşum ve bununla ilişkilenmiş gömülü mesiodens dişleri bulunan 11 yaşındaki çocuk hastaya multidisipliner tedavi yaklaşımı sunulmuştur.

\section{OLGU SUNUMU}

On bir yaşındaki erkek hasta, bir yıl önce geçirdiği travma sebebiyle santral dişinin kırılması ve çürümesi şikayetiyle Kocaeli Üniversitesi Diş Hekimliği Fakültesi Pedodonti Anabilim Dalına başvurmuştur. Medikal herhangi bir problemi bulunmayan olgunun klinik muayenesinde sağ üst santral dişinde komplike olmayan kron kırığ bulunduğu aynı zamanda kırık bölgesinde çürük oluştuğu görülmüştür (Şekil 1A). Yine sol ve sağ alt santral ve sol üst lateral ve kanin dişlerde aproksimal çürük, sol ve sağ üst ve sol alt daimi 1. molar dişlerinde okluzal çürük bulunduğu tespit edilmiştir. Ağız içerisinde eksik olan sağ ve sol alt süt 1 . ve 2 . molar dişlerin aşırı madde kaybı nedeniyle daha önce başka bir hekim tarafından çekildiği öğrenilmiştir. Yapılan radyolojik muayenede sağ üst santral dişin apikal gelişiminin tamamlanmadiğ görülürken, apikal bölgede unilokuler, sınırları belirgin radyolusent bir oluşum izlenmiştir (Şekil 2 ve 3A). Aynı zamanda maksiller anterior bölgede iki adet sürmemiş mesiodens varlı̆̆ 1 tespit edilmiş ve mesiodensler sağ üst santral dişin apikalindeki lezyon ile ilişkili olarak izlenmiştir. Klinik ve radyografik inceleme sonucunda sağ üst santral dişin apikalindeki lezyonun radiküler ya da dentigeröz kist olabileceği düşünülmüştür.

Kök gelişimi tamamlanmamış olan dişin kök kanal tedavisi ve ardından gömülü mesiodenslerin cerrahi olarak çekimi, lezyonun enükleasyonu ve aynı seans sağ üst santral dişin retrograd dolgusunun tamamlanması planlanmıştır. Hasta ve ebeveyni tedavi planlaması hakkında aydınlatılmış ve tedavi konusunda yazılı olarak onam alınmıştır. Sağ üst santral dişin giriş kavitesi

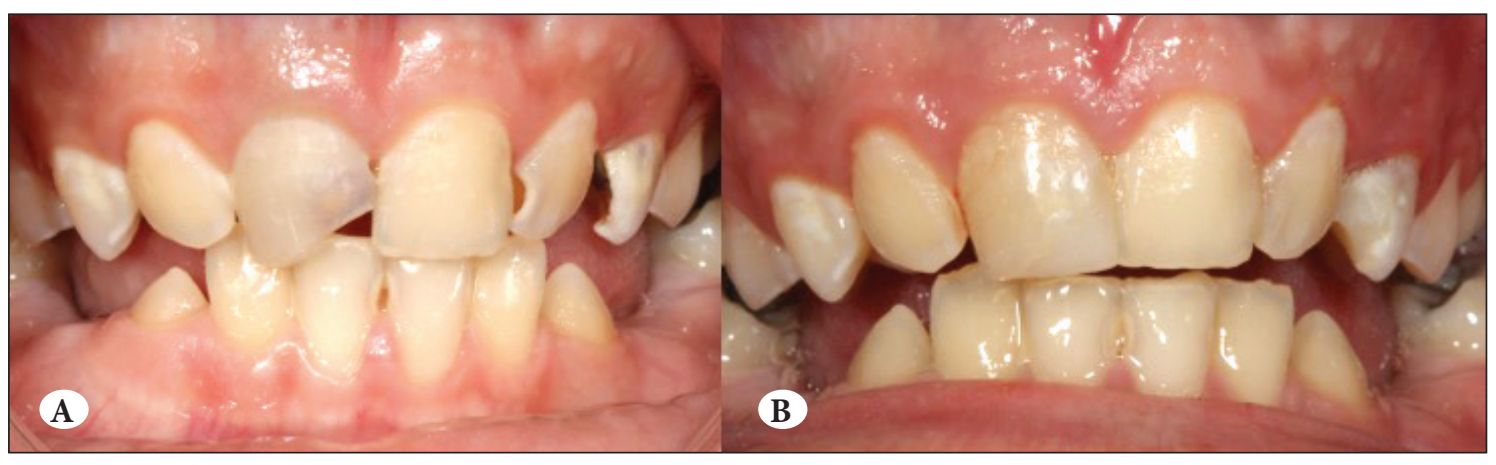

Şekil 1: Olgu’ ya ait, A) tedavi öncesi intraoral görüntü B) tedavi sonrasi intraoral görüntü. 
açılmış, kanal şekillendirmesi ve irrigasyonu gerçekleştirilmiştir. Diş semptomsuz duruma gelene kadar rutin kalsiyum hidroksit pansumanlarına devam edilmiştir. Asemptomatik hale gelen dişin kanal tedavisinde gütaperka (DiaDent Group. International Inc., Kore) ve AH Plus kanal dolgu patı (Dentsply DeTrey, Konstanz, Almanya) kullanılmıştır. Dolum işlemi lateral kondensasyon tekniği kullanılarak gerçekleştirilmiştir. (Şekil 3B). Kanal dolumunun gerçekleştirilmesini takiben ilgili dişin kompozit rezin (Kuraray Noritake Dental Inc., Okayama, Japonya) ile restorasyonu tamamlanmıştır (Şekil 1B). Aynı gün palatinalde sağ ve sol üst 1 . premolar dișler arasından, bukkalde ise sağ üst lateral ve sol üst santral dişler arasından tam kalınlık mukoperi-

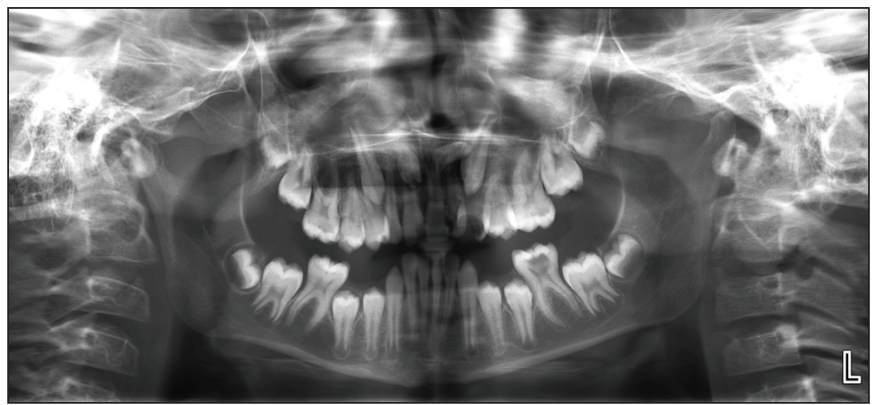

Şekil 2: Olgu'ya ait tedavi öncesi panaromik radyografi görüntüsü
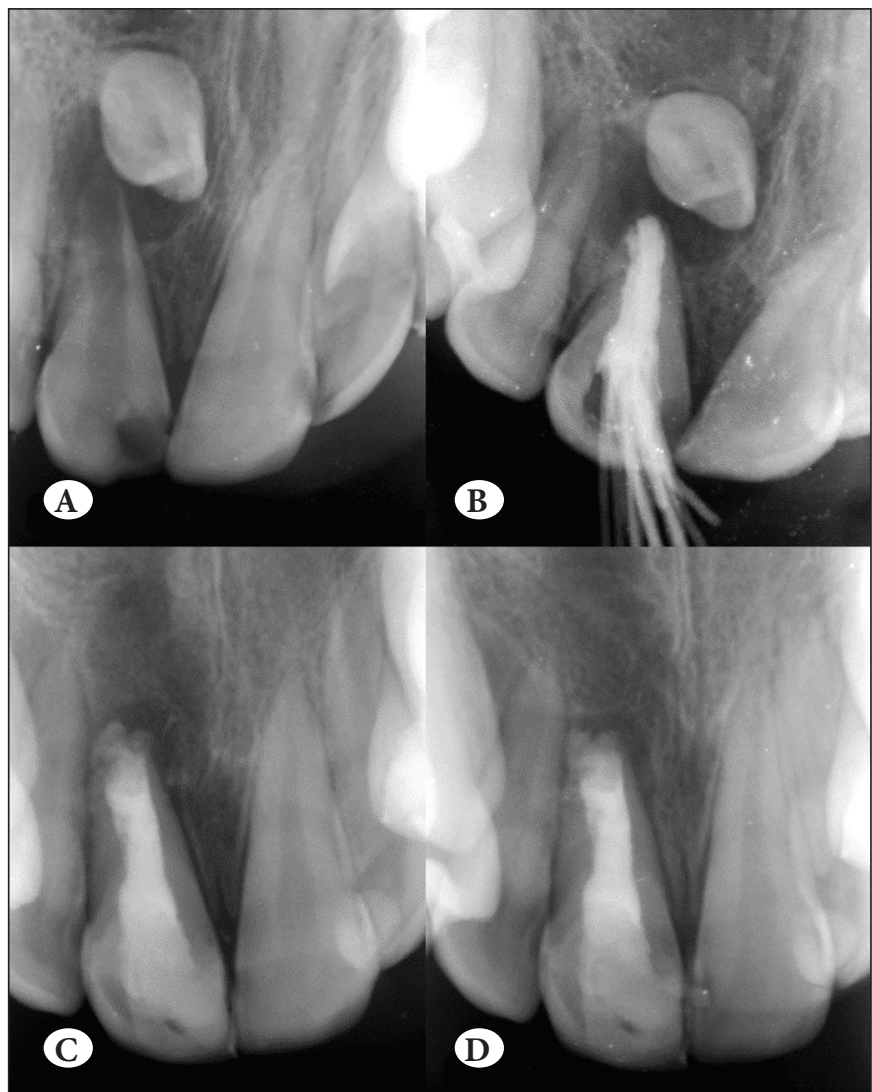

Şekil 3: Kron kırıklı dişe ait periapikal radyografi görüntüleri, A) tedavi öncesi, B) kanal tedavi sonrasi, C) 6. ay kontrol seans1, D) 1.y1l kontrol seans1.
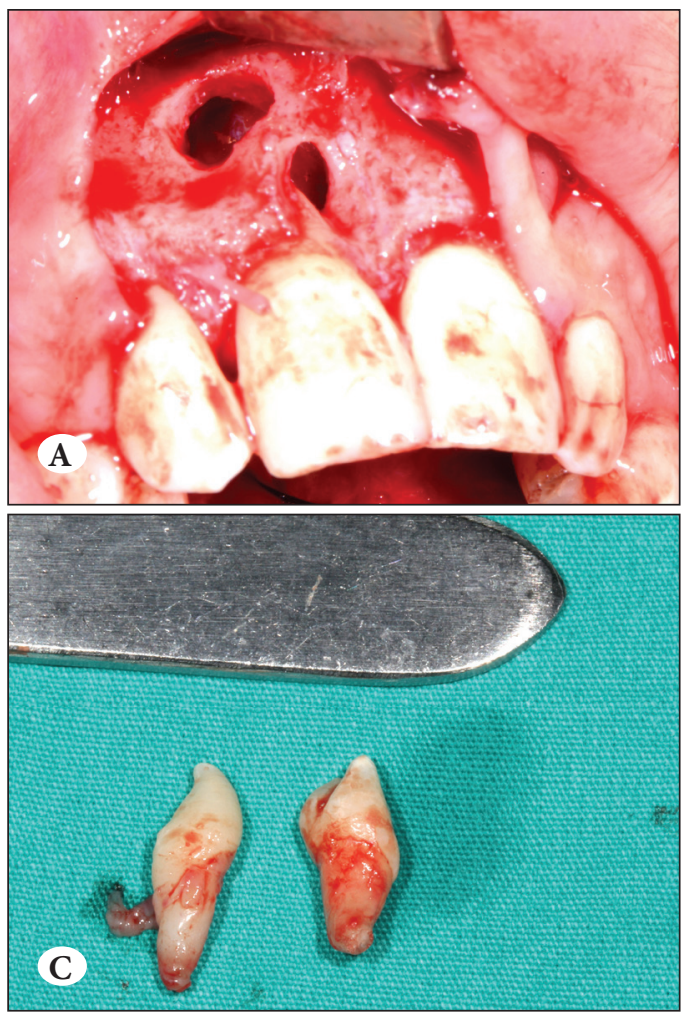
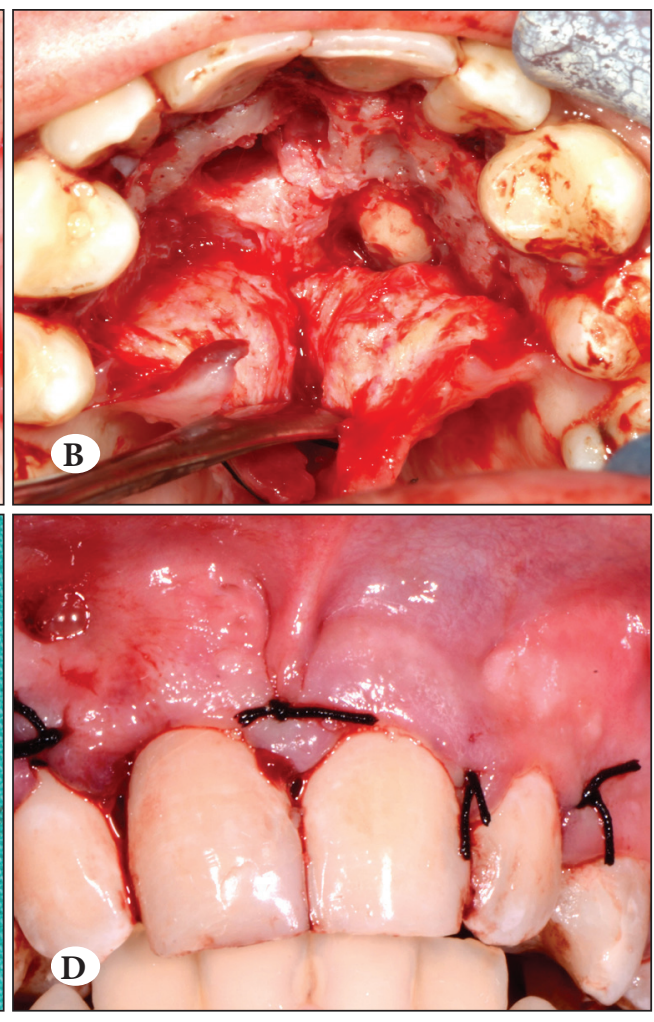

Şekil 4: Olgu'ya ait cerrahi müdahale aşamasındaki görüntüler; A,B) bukkal ve palatinal bölgeden mukoperiosteal flap kaldırılması, C) alınan gömülü mesiodensler, D) operasyon bölgesinin primer olarak kapatılması. 


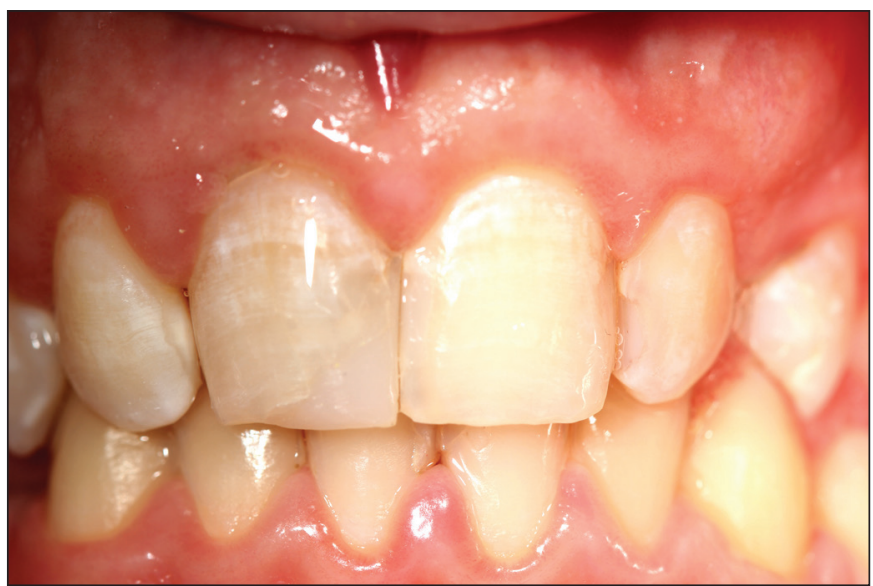

Şekil 5: Hastanın 1. yıl kontrolündeki intraoral görüntüsü.

osteal flap kaldırılmıştır (Şekil 4 A,B). Steril rond frez ile düşük hızda kemiğin kaldırılmasını takiben iki adet olan mesiodens çıkartılmıştır (Şekil 4C). Sağ üst santral dişin apikalindeki lezyon eksize edildikten sonra kök ucunda retrograd olarak MTA apikal tıkaç oluşturulmuş ve flap primer olarak kapatılmıştır (Şekil 4d). Hastaya amoksisilin grubu antibiyotik reçete edilmiş, beraberinde bir hafta boyunca yumuşak diyet ve günde iki defa olmak üzere klorheksidinli gargara yapması önerilmiştir. Eksize edilen lezyonun histopatolojik incelemesinde döşeyici skuamoz epitel varlığı saptanması nedeniyle lezyon radiküler kist ile uyumlu olarak değerlendirilmiştir. Hastanın 6.ay (Şekil 3c) ve 1 yıllık takibinde (Şekil 3d) apikalde iyileşme radyografik olarak izlenmiş ve hastanın estetiğinden memnun olduğu öğrenilmiştir (Şekil 5).

\section{TARTIŞMA}

Gömülü meziodenslerin çıkartılması için gereken ideal zamanlama son derece tartışmalı bir konudur. Acil yaklaşım ya da geç müdahale açısından hekimlerin genellikle bir ikilem yaşadığı ve bu konuda araştırmacıların değişik görüşlere sahip oldukları bildirilmektedir. Komşu dişte oluşturulabilecek potansiyel bir zararın dişin devitalizasyonu ya da kök malformasyonuyla sonuçlanabilmesi ve çocuk hastanın cerrahi müdahaleyi psikolojik olarak tolere etmeye hazır olmaması erken müdahalenin risk ve dezavantajları arasında yer almaktadır $(6,13)$. Tedavi edilmemiş bir mesiodensin oluşturabileceği komplikasyonlar ise mesiodensin üzerinde yer alan daimi kesici dişlerin geç sürmesi, rotasyonlu sürmesi, gömülü kalması, diestemalı sürmesi, kök rezopsiyonu ya da pulpa devitalizasyonu içermesi şeklindedir (10). Kistik oluşumlara neden olması veya nazal erupsiyon ise daha nadir görülen komplikasyonlar olarak bildirilmektedir (9). Son yillarda bunlara ek olarak mesiodenslerin travma olgularının oluşumunda bir predispozan faktör olabileceği ve ayrıca dental travmatik olguların tedavi aşamasında komplikasyonlara neden olabileceği yönünde sinırlı sayıda da olsa olgu raporları bildirilmektedir $(6,7)$.

Alaçam ve ark. (7) travmatik dental yaralanmayı takiben bir saat içerisinde süt içerisinde muhafaza edilmiş ve apikalinde gömülü mesiodensin bulunduğu immatür üst santral dişi reimplante ettikleri olgularında, travma tedavisinin eksternal rezorpsiyona bağlı olarak başarısızlıkla sonuçlandığını bildirmişlerdir. Yine aynı araştırmacılar (7) bir diğer olguda sürmüş olan mesiodensin travma sırasında ilişiğinde bulunan ve sürmekte olan üst daimi santral dişte komplike olmayan kron kırığına neden olduğunu bildirmişler ve mesiodens olgularının travma olgularında bir risk faktörü olduğu sonucuna varmışlardır. Kupietzky ve ark. (6) yine apikal bölgesinde bir mesiodensle ilişkili bulunan intrüzyona uğramış daimi üst santral dişin ortodontik ekstrüzyon ve beraberinde kanal tedavisini gerçekleştirmiş, mesiodensin alınmasını ertelemiş, travma olgusunu komplikeleştirmesine rağmen başarılı sonuçlar elde edildiğini bildirmiştir. Bu olgulardan farklı olarak olgumuzda hasta travma üzerinden bir yıl geçtikten sonra kliniğimize başvurmuş ve yapılan radyografik tetkikte mesiodensle ilişkili dişin apikalinde lezyon varlığ 1 ile karşılaşılmış, ayrıca lezyonun supernumerer dişten mi yoksa travmaya uğramış dişten mi kaynaklandığı konusunda ikilem yaşanmıştır. Yapılan vitalite testinin negatif olması, dişin maturasyonunu tamamlamamış olması, mesiodens de içeren bir lezyon varlığ 1 ve bu nedenle cerrahi bir operasyon gerektiği de göz önünde bulundurularak apeksifikasyon yerine kanal tedavisinin tamamlandığı seans mesiodenslerin alınması ve immature dişin kök ucunun retrograd olarak kapatılması planlanmıştır. Samuel ve ark. (14) olgumuzda olduğu gibi üst daimi santral dişinde oluşan kron kırığını takiben bir ay sonunda başvuran hastanın radyografik muayenesinde kırık dişle ilişkili iki süpernumerer diş varlığ 1 tespit etmiştir. Ancak olgumuzdan farklı olarak travma geçiren dişin lezyon içermemesi ve kök formasyonunun tamamlanmış olması nedeniyle araştırmacılar kanal tedavisini tamamladıktan sonra mesiodensleri cerrahi olarak almış ve tedavinin üç yıllık takibinde herhangi bir komplikasyonla karşılaşılmadıklarını bildirilmişlerdir. Benzer şekilde Sharma ve ark.(15) üç yıl önce travma geçiren olgunun sağ üst santral dişinde kron kırığı bulunduğunu tespit edip, apeksifikasyonu tamamlanmamış olan dişin vitalitesini kaybettiğini rapor etmişlerdir. Olgunun radyografik incelemesinde santral dişin apika- 
linde lezyon varlığ 1 ve bu lezyonun iki adet mesiodens ile ilișkide olduğunu bildirmişlerdir. Olgumuzla oldukça benzerlik gösteren olgularının tedavisinde endodontik tedavi ve cerrahi olarak mesiodens dişlerin ve lezyonun enükleasyonunu planlamışlardır. Ancak; Sharma ve ark. (15) eksize ettikleri oluşumun dentigeröz kist ile uyumlu olduğunu rapor ederken, olgumuzda eksize edilen lezyonun radiküler kist ile uyumlu olduğu tespit edilmiştir. Radiküler kistlerin inflamatuar kaynaklı ve sıklıkla çürük ve devital dişlerle ilişkili olduğu göz önüne alındığında, bu durum olgumuzda kist oluşumunu, travmaya maruz kalan ve tedavi edilmeyen, bunun sonucunda devital hale gelen sağ üst daimi santral dişin indüklediği, diğer olguda ise aslında meydana gelen kistin, sürmemiş olan mesiodensin folikülünden kaynaklandığını düşündürmektedir. Bununla birlikte literatürde Sharma ve ark. (15)' nın olgularına benzer şekilde süt dişlerine gelen travma ile altında ilişkili bulunan daimi dişin etrafında bulunan dentigeröz kist olgularıbildirilmesi travmaya maruz kalan dişlerin kist oluşumuna direkt sebebiyet vermese de, travmaya uğramış dişin apikaline yakın konumlanmış olan gömülü herhangi bir diş varlığında (sürnümerer veya henüz sürmemiş daimi dişler) foliküler kaynaklı kist oluşumunu tetikleyebileceği düşüncesini akla getirmektedir $(15,16,17)$.

$\mathrm{Bu}$ olgu sunumunda kron kırığı kaynaklı bir radiküler kist ve ilişiğinde bulunan gömülü mesiodenslerin kanal tedavi ve takibinde cerrahi müdahale ile gerçekleştirilen multidispliner yaklaşımı anlatılmıştır. Dental yaralanmalar arasında basit sayılabilecek olan kron kırığı bulunan diş asemptomatik olduğu için ebeveynin durumu önemsememesi ve zamanında tedavi için müracaatta bulunmadığından devital hale gelmiş ve kistik oluşuma neden olmuştur. Aynı olguda mesiodenslerin varlığı radyografik muayenede tesadüfen tespit edilmiştir. $\mathrm{Bu}$ nedenle toplumun dental travmalar sonrası acil müdahalenin gerekliliği ve rutin dental muayenelerin önemi konusunda farkındalığının artırılması için pedodontislere büyük görev düşmektedir.

\section{KAYNAKLAR}

1. Andreasen FM, Andreasen JO. Crown fractures. Textbook and color atlas of traumatic injuries to the teeth. 3rd ed. Copenhagen Munksgaard; 1994. 219-56.

2. Wilson S, Smith GA, Preisch J, Casamassimo PS. Epidemiology of dental trauma treated in an urban pediatric emergency department. Pediatr Emerg Care 1997; 13: 12-5.
3. Bastone EB, Freer TJ, McNamara JR. Epidemiology of dental trauma: a review of the literature. Aust Dent J 2000; 45: 2-9.

4. Andreasen JO, Jensen SS, Varawan S. The role of antibiotics in preventing healing complications after traumatic dental injuries: a literature review. Endod Topics 2010; 14: 80-92.

5. Waterhouse PJ, Whitworth JM, Camp JH, Fuks AB. Chapter 23, Pediatric endodontics: endodontic treatmentfor the primary and young permanent dentition. In:Hargreaves KM, Cohen S, editors. Cohen's Pathways of the pulp. 10th ed. St Louis Mosby Elsevier; 2011. 808-857.

6. Kupietzky A, Rotstein I, Kischinovsky D. A multidisciplinary approach to the treatment of an intruded maxillary permanent incisor complicated by the presence of two mesiodentes. Pediatr Dent 2000; 22: 499-503.

7. Alaçam A, Bani M. Mesiodens as a risk factor in treatment of trauma cases. Dent Traumatol 2009; 25: 25-31.

8. Mason C,Azam N, Holt RD, Rule DC. A retrospective study of unerupted maxillary incisors associated with supernumerary teeth. Br J Oral Maxillofac Surg 2000; 38 : 62-5.

9. Stellzig A, Basdra EK, Komposch G. Mesiodentes: incidence, morphology, etiology. J Orofac Orthop 1997; 58: $144-53$.

10. Russell KA, Folwarczna MA. Mesiodens - diagnosis and managementof a common supernumerary tooth. J Can Dent Assoc 2003; 69: 362-6.

11. Garvey MT, Barry HJ, Blake M. Supernumerary teeth: An overview of classification, diagnosis and management. J Can Dent Assoc 1999; 65: 612-6.

12. Frost DE, Hersch EV, Levin LM. Anasthesia/Dentoalveolar surgery/ Office management. In: Fonseca RJ, editor. Oral andMaxillofacial Surgery. 1st ed. Philadelphia WB Saunders; 2000. 356-362.

13. Omer RS, Anthonappa RP, King NM. Determination of the optimum time for surgical removal of unerupted anterior supernumerary teeth. Pediatr Dent 2010; 32: 14-20.

14. Samuel AV, RM, Gupta YM. Management of Complicated Crown Fracture and Associated Impacted MesiodensCase Report with 3yrs Follow-up. J Clin Diagn Res 2014; 8: 32-3.

15. Sharma D, Garg S, Singh G, Swami S. Trauma-induced dentigerous cyst involving an inverted impacted mesiodens: case report. Dent Traumatol 2010; 26: 289-91.

16. Gondim JO, Neto JJ, Nogueira RL, Giro EM. Conservative management of a dentigerous cyst secondary to primary tooth trauma. Dent Traumatol 2008; 24: 676-9.

17. Bharath KP, Revathy V, Poornima S, Subba Reddy VV. Dentigerous cyst in an uncommon site: a rare entity. J Indian Soc Pedod Prev Dent 2011; 29: 99-103. 